\title{
Educação popular em saúde, arte e múltiplas linguagens ${ }^{1}$
}

\author{
Vera Lúcia de Azevedo Dantas², César Augusto Paro ${ }^{3}$, Pedro José Santos Carneiro Cruz ${ }^{4}$
}

\begin{abstract}
Resumo
Era uma vez um texto-provocação construído por seis mãos. Essas mãos pertenciam a três corações e a três mentes de três seres que vinham experimentando em seu cotidiano acadêmico-profissional a potência do sensível. Encharcadas de alegria e afetos, essas mãos teciam algumas reflexões sobre as potencialidades da arte e das múltiplas linguagens no campo da Educação Popular em Saúde e a contribuição dos investimentos na dimensão estética para a ampliação das possibilidades de ação, de produção de conhecimentos e de desvelamento de processos de ensino e de aprendizagens com olhar crítico, participativo, emancipador e, sobretudo, criativo, inclusivo e amoroso. Em diálogo com outros artistas, filósofos e educadores, ensaiavam, ora proseando, ora versificando, sobre alguns desafios que rondam esta intersecção, mas também a potência dessa mistura. Fim! - Ou, na verdade, como você leitor/a vai ver ao final: Fim que sai para dar passagem para uns vários outros tantos começos!
\end{abstract}

\section{Palavras-chave}

Arte. Linguagens. Sensível. Emancipação. Educação Popular em Saúde.

${ }^{1}$ Esse texto deriva das reflexões construídas coletivamente durante o Painel Temático "Diálogo da Educação Popular em Saúde e as múltiplas linguagens" do II Seminário Temático do Grupo Temático de Educação Popular e Saúde da Associação Brasileira de Saúde Coletiva (GT EPS/ABRASCO), ocorrido nos dias 4 e 5 de fevereiro de 2020, em Parnaíba, Piauí, Brasil.

${ }^{2}$ Artista, como todo ser humano. Doutora em Educação pela Universidade Federal do Ceará, Brasil; médica da Estratégia Saúde da Família da Secretaria Municipal de Saúde de Fortaleza, Ceará, Brasil; integrante do Coletivo Gestor do Espaço Ekobé e do Núcleo de Coordenação do GT EPS/ABRASCO. E-mail: dantas.verinha@gmail.com.

3 Artista, como todo ser humano. Doutorando no Programa de Pós-Graduação em Saúde Coletiva da Universidade Federal do Rio de Janeiro, Brasil, com período sanduíche na Seção de Saúde Global da Universidade de Copenhagen, Dinamarca; integrante do Grupo de Estudos em Teatro do Oprimido (GESTO) e do GT EPS/ABRASCO. E-mail: cesaraugustoparo@iesc.ufrj.br.

${ }^{4}$ Artista, como todo ser humano. Doutor em Educação pela Universidade Federal da Paraíba, Brasil; professor do Departamento de Promoção da Saúde do Centro de Ciências Médicas na mesma instituição; integrante do GT EPS/ABRASCO. E-mail: pedrojosecruzpb@yahoo.com.br. 


\title{
Popular health education, art, and multiple languages ${ }^{5}$
}

\author{
Vera Lúcia de Azevedo Dantas ${ }^{6}$, César Augusto Paro ${ }^{7}$, Pedro José Santos Carneiro Cruz ${ }^{8}$
}

\begin{abstract}
Once upon a time, there was a text-provocation written by six hands. These six hands belonged to three hearts and three minds of three subjects who have been experiencing the potentiality of the sensible in their academic and professional quotidian. Moved by happiness and affections, these hands wove some reflections about the possibilities of art and the multiple languages to the field of popular health education. The thoughts also included the contributions of investing in the aesthetic dimension to expand the possibilities of actions, of knowledge production, and of teaching-learning processes with a critical, participatory, emancipating, and, above all, creative, inclusive, and lovely perspective. Their writings sometimes were presented by verse, other times by prose. While talking with other artists, philosophers, and educators, the hands rehearsed the challenges and the potentialities that happen when the popular health education intersects with the art and multiples languages. The end! Or, actually, as you, dear reader, will read at the final of this paper: The end is getting out now to allow the beginning of a lot of other starts!
\end{abstract}

\section{Keywords}

Art. Languages. Sensible. Emancipation. Popular Health Education.

\footnotetext{
${ }^{5}$ This production is based on the collective reflections of the conference panel "Dialogues between the Popular Health Education and the multiple languages" presented in the II Thematic Seminar of the Thematic Group for Popular Education and Health of the Brazilian Association of Collective Health (Brazilian acronym GT EPS/ABRASCO). It occurred from $4^{\text {th }}$ to $5^{\text {th }}$ February 2000 in Parnaíba, State of Piauí, Brazil.

${ }^{6}$ Artist, as all human beings. PhD in Education, Federal University of Ceará, Brazil; physician of the Family Health Strategy, Municipal Health Secretariat of Fortaleza, State of Ceará, Brazil; member of the Collective Manager of Espaço Ekobé and the Coordination Group of GT EPS/ABRASCO. E-mail: dantas.verinha@gmail.com.

${ }^{7}$ Artist, as all human beings. PhD student in the Postgraduate Program in Collective Health, Federal University of Rio de Janeiro, Brazil, with a sandwich period at the Global Health Section of the University of Copenhagen, Denmark; member of the Study Group on Theater of the Oppressed (GESTO) and the GT EPS/ABRASCO. E-mail: cesaraugustoparo@iesc.ufrj.br.

${ }^{8}$ Artist, as all human beings. PhD in Education, Federal University of Paraíba, Brazil; professor at the Health Promotion Department at the Medical Sciences Center in the same institution; member of GT EPS/ABRASCO. E-mail: pedrojosecruzpb@yahoo.com.br.
} 


\section{"Ô abre alas que eu quero passar": notas introdutórias sobre os afetos e as alegrias que nos encharcam para tecer este diálogo}

A educação popular trouxe para o campo da Saúde Coletiva dimensões como a problematização, o agir crítico-reflexivo e a assunção de uma intencionalidade política emancipatória. Tais dimensões apresentam-se como provocações potentes no sentido de fortalecer o pensar e o agir em Saúde Coletiva na direção de sua constituição, tanto enquanto campo de conhecimento, quanto como prática profissional, social, educativa e comunitária.

Ainda merece destaque como contribuição dessa concepção educativa a proposta da amorosidade e a potência que ela desvela como princípio pedagógico: Paulo Freire (2016a) nos convida a pensar sobre a importância dos afetos nos processos de aprender, de ensinar e de produzir conhecimentos. Provoca-nos também a pensar que educadores e educandos conduzam seus processos estando compromissados por inteiro, no sentido de, por meio de seu agir, dedicarem esforços para a promoção integral do ser do outro e da outra, em um processo que busca, também, se pautar em uma visão integral do ser humano. Sendo humano por inteiro, há que se promover por inteiro o humano no outro e na outra, justamente por ser o amor a esse outro e a essa outra uma condição ética fundante e mobilizadora da ação educativa em si.

Corroborando com a proposição freiriana, Baruch Spinoza (1997) já nos dizia no século XVII que o afeto possui uma potência de agir que se manifesta também no corpo, que as ideias que nutrem esses afetos também possuem uma potência de ação. As paixões alegres nascem da compatibilidade entre suas causas exteriores e o nosso mundo interno e aumentam nossa potência de agir e de pensar ao fortalecer o que chamou de esforço de existir ou conatus. Para Spinoza, são fortes os afetos nascidos das paixões alegres, no interior das quais, fortalecidos em nossa potência de existir, podemos passar à ação.

O percurso pedagógico pautado pela educação popular faz emergir processos nos quais, por caminhos orientados pela amorosidade, pelos afetos e pela alegria, os saberes-deexperiência-feito dos sujeitos e dos coletivos com suas culturas não sejam apenas meramente reconhecidos, mas sejam levados em conta nos trabalhos sociais com ênfase crítico-reflexiva e com intencionalidade emancipatória. Nessa direção, as experiências que temos vivido no Brasil e em outros países da América Latina nos falam das possibilidades criativas de unir essas questões, especialmente ao incorporar a arte e suas múltiplas linguagens.

\footnotetext{
${ }^{9}$ Trecho de "Ô abre alas", primeira marchinha de carnaval brasileira, composta por Chiquinha Gonzaga.
} 
Diante do exposto, iremos, nas páginas a seguir, tecer algumas reflexões sobre as potencialidades da arte e das múltiplas linguagens no campo da Educação Popular em Saúde (EPS) e como essas contribuem para a ampliação das possibilidades de ação, de produção de conhecimentos e de desvelamento de processos de ensino e de aprendizagens com olhar crítico, participativo, emancipador e, sobretudo, criativo, inclusivo e amoroso.

Embasamos nossas formulações a partir de conhecimentos referendados por alguns elementos que consideramos fundamentais no contexto de experiências que temos vivenciado no Ceará, no Rio de Janeiro, na Paraíba e em outros recantos do Brasil, como trilhas de educação popular, e que têm sido base, esteio, para que essas histórias de luta e resistência se efetivem gerando discursos que não se expressam de forma fragmentada, mas em sua inteireza, em que seres individuais e coletivos se expressam de forma polifônica em múltiplas linguagens. Em especial, compartilham-se elaborações coletivamente constituídas em espaços do Grupo Temático de EPS da Associação Brasileira de Saúde Coletiva (ABRASCO).

\section{"Guarda num velho baú seus instrumentos de trabalho/1 abridor de amanhecer/1 prego que farfalha/1 encolhedor de rios/1 esticador de horizontes" ${ }^{10}$ : dos sensíveis que ampliam horizontes por meio de suas potências emancipadoras}

Compreendemos a arte como um dos modos dos seres humanos serem, estarem e dialogarem com e no mundo, dada a nossa própria capacidade de construir atos-criadores que fazem emergir uma imensidão de novas linguagens, trazendo uma dimensão estética à existência humana. Afinal, como aponta o teatrólogo carioca Augusto Boal (2009, p. 138), "ser humano é ser artista e ser artista é ser humano. Arte é vocação humana, é o que de mais humano existe no ser".

No entanto, tanto por conta do modo como a arte foi relegada do povo para ser colocada numa lógica coercitiva em que a produção artística de alguns poucos deveria ser consumida por outros muitos (BOAL, 2009), quanto por conta do isolamento que o fazer científico racional-universalista foi tendo das outras dimensões humanas por conta de ser considerado como o porta-voz da Verdade (WONG-UN, 2017), refletir sobre a arte no contexto da produção de saúde é um caminho cheio de tensionamentos. Tais tensões podem ser vislumbradas em polarizações como: entre a arte e a racionalidade, entre a arte e a ciência, entre a arte como uma dimensão humana e a arte com um viés meramente instrumental, entre

\footnotetext{
${ }^{10}$ Poema de Manoel de Barros publicado em O livro das ignorãças.
} 
a arte como possibilidade de ser e a arte como ode a um único jeito de ser, entre a arte como problematização/construção do mundo e a arte como aceitação/adaptação ao mundo já dado, entre os processos artísticos que cotejam a dialeticidade da relação subjetividade-objetividade e os processos que caminham por um solipsismo subjetivista.

É buscando superar alguma das visões restritas acima e reconectar a arte ao povo e à produção de saúde, que enfatizemos a potência transformadora da arte. Como nos ensina Nietzsche (1996), a arte é potência de vida. E, situando-se como espaço-movimento de expressões múltiplas, a arte parece-nos despertar as paixões alegres a que se referia Spinoza.

Assumindo um agir transformador, a prática artística conecta-se a uma matriz política. Por isso que, ao falar da arte no fazer educativo, estamos falando de "uma educação política e estética que inclua um trabalho do conhecer a partir dos processos de pensamento que se usam em arte e que se vinculam estreitamente aos padrões do sentir humano" (LINHARES, 2003, p. 44).

Desse modo, a educação popular, especialmente em suas realizações no campo da saúde, referencia a arte e a cultura como processo no qual as pessoas, os grupos e as classes populares expressam e simbolizam sua representação, recriação e reelaboração da realidade, inserindo-as em uma prática social libertadora, cujas expressões não se separam da vida cotidiana.

A arte consegue contribuir fundamentalmente no acolhimento dos diferentes sentires, pensares e agires que são produzidos e compartilhados cotidianamente na complexa dinâmica da vida nos vários territórios. Em qualquer contexto de atividade educacional, a arte permite que tais aspectos - constituídos essencialmente a partir dos sentidos dos outros e das outras possam ser expressados. Quando há discussão de qualquer assunto em tal atividade, a arte contribui para que as pessoas - com seu jeito, seu olhar e sua cultura - se sintam à vontade para colocar em pauta os temas palpitantes, ou seja, as principais questões e as preocupações importantes de seus respectivos contextos. Assim, não apenas as pessoas são centrais no processo educativo, mas fundamentalmente são fundantes as questões que detêm sentido para a vida dessas pessoas e utilidade prática, de modo que a problematização e a reflexão em cima dessas questões possa efetivamente contribuir para que as pessoas consigam viver melhor em seus territórios ou trabalhar melhor em seus diferentes espaços e contextos. Justamente por acolher os sentidos das pessoas - expressos em seus sentires, pensares e agires - traduzidos pelas formas como as pessoas culturalmente sabem enunciar tais sentidos, que a arte contribui substancialmente para posicionar os atores do campo popular e seus conhecimentos como protagonistas dos processos de ensino e de aprendizagem. 
Parece-nos, então, que a arte, em suas múltiplas linguagens, nos traz a possibilidade de vivenciar um fazer em saúde no qual o processo criativo que se instaura agrega outras dimensões que não só a racional, reconhecendo a estética popular capaz de produzir sentidos e sentimentos (BRASIL, 2012).

Caminhando por essa ideia, podemos perceber que a arte enseja a produção de um processo de ensino e de aprendizagem que vem encharcado de sentidos humanos, pois suas trilhas de produção têm como pressupostos o reconhecimento de que o ser humano não é apenas produtor de raciocínios "racionalizantes", mas também é produtor de sentidos que estão permeados de especificidades subjetivas, de sutilezas, de complexidades, de interconexões com o ambiente, com espiritualidades, com a fé e com as emoções. Nesses sentidos, a arte humaniza mais profundamente o processo de ensino e de aprendizagem na medida em que não omite os sentidos humanos que fazem parte do viver. Orienta, referencia e pauta a produção do conhecimento e o processo de ensino e de aprendizagem pelo concreto vivido, conforme sentido e interpretado pelas pessoas.

A abordagem da arte e das múltiplas linguagens nas práticas sociais e no agir profissional, em nosso ver, radicaliza a possibilidade de que os processos formativos sejam orientados pela realidade humana conforme essa realidade é sentida e expressada pelas pessoas em todas as suas dimensões complexas e multifacetadas, bem como pelas e nas relações construídas entre as pessoas. Nesse sentido, a arte mobiliza as pessoas a expressarem, inclusive, as determinações sociais, econômicas e políticas as quais as pessoas estão expostas, ao evidenciar como as pessoas sentem, vivenciam e percebem essas determinações, bem como a forma como respondem as mesmas.

Nessa direção, trazemos aqui a potencialidade da arte em ser propulsora de um pensar que envolve outras dimensões além da razão "racionalizante", e, com certeza, muito além da perspectiva "racionalista". É uma razão que se faz crítica na medida em que se faz, de forma integral e integrada, razão raciocinante, razão pensante, razão emocionadora, razão emotiva, razão sensível, razão amorosa, razão indignada, razão acolhedora do misterioso, do inusitado, do desconhecido. Razão que tem ânsia de ser provocada a ser mais e a conhecer melhor. Em outras palavras, a arte traz, na verdade, uma razão que fala não só a partir da mente, mas também do afeto, a partir das espiritualidades, da forma como as pessoas entendem a existência e a interpretam. 
Compor-com-arte os processos educativos nos permite, portanto, ampliar horizontes para nos educarmos. A arte nos traz a possibilidade de se acolher as formas diversas das pessoas expressarem com liberdade, autonomia e amor seu olhar sobre o mundo, seu cotidiano de estratégias de resistência diante das situações-limite. É uma composição que traz à baila a sensibilidade para nos conectar com o outro, e, assim, ensejar a construção de novos modos de se viver e promover a coletividade - elemento essencial para que possamos juntos analisar criticamente as situações-limite e também juntos sonhar nossos inéditos viáveis para superação destes desafios.

\section{“Deuclides, a 'personificação’ de Oxalá, reúne os outros oborós e celebra: ‘Quando o rebanho se une, o leão dorme com fome. Axé!" " ${ }^{11}$ : radicalizando uma concepção popular de arte, de educação, de ação social e de produção do conhecimento}

Em nossa visão, os processos educativos permeados pela arte e pelas múltiplas linguagens da cultura popular podem construir um olhar sobre a cultura que seja respeitoso e compromissado com a promoção integral dos modos de andar a vida das pessoas, referenciados por relações horizontais entre os sujeitos do processo.

Assim, trazer à cena a reflexão sobre educação popular em seus diálogos com a arte, a cultura popular e suas múltiplas linguagens nos remete a buscar caminhos que ousem abstrair da prática cotidiana as questões que vão permitir olhar criticamente sobre ela, problematizá-la e construir coletivamente atos de superação. Remete-nos a falar de uma perspectiva popular.

Em nossa visão, popular passa pelo olhar dos atores e das atrizes dos movimentos populares que protagonizam ações de transformação das situações-limite da sua realidade, sempre na perspectiva da emancipação social, humana e política da coletividade. Um popular que constitui princípios éticos e filosóficos tecidos pela busca humana pela superação da consciência ingênua rumo à mobilização de esforços de pensamento e de ação capazes de ensejar a construção de inéditos-viáveis. Popular como atitude reconhecedora do inacabamento e da formação permanente das pessoas.

Na acepção de José Francisco de Melo Neto (2014, p. 28), o popular, necessariamente, possui "uma plasticidade conceitual, exigindo, para os dias de hoje, uma definição que, rigorosamente, passa por movimentos dialéticos intrínsecos ao próprio conceito, inserido no

\footnotetext{
${ }^{11}$ Trecho do espetáculo teatral Oboró - masculinidades negras, dramaturgia do carioca Adalberto Neto.
} 
marco teórico da tradição e atualizado para as atuais exigências”. O popular é um conceito que

\begin{abstract}
arrasta para si definições envolvendo as utopias tão necessárias para os dias atuais. Ser popular é tentar alternativas. É estar realizando o possível, mas que, ao se realizar, abre, contraditoriamente, novas possibilidades de utopias, cuja negação trará os elementos já realizados e tentativas de novas realizações. Isto só ocorre, contudo, quando da sua realização mesma, caminhando para aquilo que, efetivamente, é o necessário: a utopia da democracia, como valor permanente a ser vivida sem qualquer entrave. Precisamente, nos espaços da realização e da não realização estão as suas contradições e suas dificuldades maiores. Entretanto, não podem transformar-se em agentes impeditivos da intransigente e radical busca por novas concretizações de sonhos de liberdade e de felicidade. (MELO NETO, 2014. p. 30).
\end{abstract}

Popular, portanto, constitui uma concepção orientadora da ação social, do processo pedagógico e da produção do conhecimento. Está carregada de determinados princípios e se orienta por uma ética que busca a justiça, a solidariedade nas relações e nas políticas. Traz a tensão permanente entre a ação política e o necessário fortalecimento da permanente organização de espaços que animem a luta popular e sua mediação com as esferas institucionais. Popular que, pelo olhar crítico das situações-limite e pela construção de inéditos-viáveis, é fundamentalmente empenhado em produzir atos-limite transformadores da realidade, atualizando sua potência criativa.

É com base nessa concepção que, quando pronunciamos arte, falamos do olhar que traz também a estética popular que nos pergunta por dimensões da vida das comunidades. Arte como caminho de diálogo, que, nas palavras de Freire (2016b, p. 109), trata-se do "encontro dos homens, mediatizados pelo mundo, para pronunciá-lo, não se esgotando, portanto, na relação eu-tu". Arte-diálogo como mobilizadores da consciência do inacabamento, como devir de sujeitos que se transformam no processo, compreendendo o diálogo como relações entre interlocutores de uma ação histórica, compartilhada socialmente, destacando assim a natureza contextual da interação, no dizer de Bakhtin (2003).

Dessa forma, a arte parece-nos se expressar nos contextos dos movimentos e práticas populares como espaço de criação - transcendência, capaz de produzir sentidos e sentimentos, contribuindo para conformar as trilhas dos caminhos, dos atos que ultrapassam limites e transformam realidades. Nesses contextos, ela parece emergir não como veículo, ou como instrumento apenas, mas como dimensão dos sujeitos que potencializa a dialogicidade capaz de realizar a suspensão crítica e criativa onde se promove a reflexão das ações. 


\section{“O movimento da poesia/É alegria/Do conviver/O movimento da poesia/Alegremia/Do Bem Viver" "12: por uma metodologia alegrêmico-poética no ensinar e no aprender humanizadores}

Pela arte, o diálogo e o processo de ensino-aprendizagem nas práticas de EPS não se dão tão somente em torno de conteúdos pré-estabelecidos, mas de uma metodologia própria a partir da qual os temas são gerados e determinados pelos educandos. Para tanto, é importante que as questões que são essenciais para os educandos sejam expressas por eles de acordo com o modo como elas afetam o seu pensar, seu sentir e seu agir. A arte é uma das melhores formas de convidar as pessoas a expressar esse sentir, pensar e agir, justamente porque consegue mobilizá-las de um modo acolhedor, convidativo e criativo para que elas expressem os sentimentos que estão construindo e que estão fazendo ressonância nos caminhos de seu viver.

Com princípios e metodologias que lhe são próprios, a arte traz para o centro do processo educativo a abertura acolhedora para a expressão de diferentes linguagens, de modo que elaboração dos problemas que servirá de base para o processo de ensino e aprendizagem poderá se dar não apenas por uma lógica racionalista, orientada pela linguagem acadêmica formal, mas, sobretudo, pela forma como as pessoas se expressam em suas culturas. Suas linguagens englobam não a língua falada, mas suas formas de falar, o seu jeito de dizer, seus caminhos e modos de pensar, como também suas formas de pronunciar e enunciar aquilo que é importante para a vida delas, do jeito como elas interpretam.

Tais elementos contribuem para que a abordagem aos problemas (que é própria da educação popular) passe a ser feita com a mobilização de sentidos significativos para as pessoas e, portanto, com maior profundidade, uma vez que, pela arte, em nosso ver, há menos obstáculos para as pessoas expressarem como se sentem, pensam e agem. Seja por um desenho, pela criação de uma música, pelo canto de uma cantiga conhecida, por cordel, por estrofe, por encenação, por brincadeiras populares, enfim, as pessoas expressarão com seu jeito e com seu olhar. A arte permite isso na medida em que é acolhedora dessas diferentes formas e não as hierarquiza nem discrimina, pelo contrário evoca o conhecimento como uma

\footnotetext{
${ }^{12}$ Cantiga composta coletivamente por educandos do Curso de Especialização e Aperfeiçoamento em Educação Popular e Promoção de Territórios Saudáveis na Convivência com o Semiárido, Fiocruz, Ceará.
} 
pintura que expressa sua boniteza com as diferentes cores ou mesmo com uma orquestra, em que o diferencial está nos vários e distintos sons.

Nessa direção, podemos constituir que a arte se expressa efetivamente como um caminho de valorização dos conhecimentos populares, pois os inclui dentro do processo educativo, os põe para circular na roda como protagonista. Nesse sentido, o conhecimento produzido por meio do ensino e da aprendizagem com a arte pela educação popular tem sua construção sendo pautada não apenas pelo raciocínio acadêmico. Nesse processo, tão importante como um texto, um artigo ou um capítulo de um livro, são também cantigas, poemas, poesias, danças, esquetes teatrais, versos, entre outras formas de manifestação. Essas outras formas poderão trazer consigo uma profundidade de conhecimentos, de perspectivas, de ideias, de propostas e de encaminhamento de ações, mesmo que não explicitados dentro de uma racionalidade acadêmica tradicional. Mesmo que com uma lógica não estruturada pelo critério formal de pensar e de elaborar.

\section{"Cuidar do outro é cuidar de mim, cuidar de mim é cuidar do mundo" ${ }^{13}$ : epidemias de afetos que contagiam encontros cuidadores}

A interface da arte com as práticas de educação popular não se trata necessariamente de um tema novo. Ao longo da história, essa dimensão sempre esteve presente nas experiências educativas com o povo, como as realizadas no contexto das experiências do Movimento de Cultura Popular e as próprias iniciativas de alfabetização de jovens e adultos desenvolvidas por Paulo Freire e sua equipe (FREIRE, 2015). Ao longo das já quase seis décadas, nas quais sujeitos operam a partir dessa concepção de agir educacional, a arte vem sendo presente como elemento intermediador de metodologias para a condução de práticas sociais com um diálogo que seja sensível, franco, aberto e o mais ampliado possível com as comunidades.

Atualmente, são muitas experiências espalhadas pelo Brasil. Práticas inovadoras fomentadas pelas redes, pelos movimentos e articulações de educação popular, entre as quais estão a Articulação Nacional de Movimentos e Práticas de EPS (ANEPS) e a Articulação Nacional de Extensão Popular (ANEPOP), que têm construído novos jeitos de fazer processos formativos e mobilizatórios como as Tendas Paulo Freire, as caravanas populares, os cursos

\footnotetext{
${ }^{13}$ Cantiga Cuidar do outro é cuidar de mim, composta por Johnson Soares, Júnio Santos e Ray Lima.
} 
de formação em/a partir da EPS e seus desdobramentos, nos quais se tem provocado o debate e transformação pelo sensível destacando o saber popular.

É a palhaçaria transformando agentes de saúde em agentes culturais de saúde por meio da dialogia do riso, dado o forte potencial pedagógico que o agir-pela-palhaçaria tem "para a construção de tecnologias sociais, que promove encanto, encontro, alegria, e, portanto, saúde" (MATRACA; WIMMER; ARAÚJO-JORGE, 2011, p. 4.135). Palhaços artivistas que se afetam com as "emoções e afetividade dos oprimidos, dos vulneráveis e sofridos" (COSTEIRA; VASCONCELOS; NASCIMENTO, 2018, p. 13).

É o Teatro do Oprimido operado em diferentes contextos "numa perspectiva crítica de reinvenção, mudança e inovação, [...] [para] que os indivíduos e coletividades possam atuar em melhorias de suas qualidades de vida e saúde" (PARO; SILVA, 2018, p. 489), como na saúde mental (SANTOS; JOCA; SOUZA, 2016), atenção básica (SILVA, 2008), desenvolvimento social (ALVES; GONTIJO; ALVES, 2013).

É a cenopoesia ${ }^{14}$ convidando-nos a compor uma ideia de polifonia como propõe Bakhtin, na qual, por meio do dialogismo, as vozes dissonantes podem se harmonizar e interagir com inteligência e respeito expressando-se em experiências por diversos recantos do nosso Brasil: no Rio Grande do Norte, com o Movimento Escambo Popular Livre de Rua (SANTOS, 2019); no Ceará, com as Cirandas da Vida e as práticas de cuidado do Espaço Ekobé (DANTAS, 2009); no Rio de Janeiro, com o Hotel da Loucura (CRUZ, 2018) e outros.

É a dança... É o repente... É o bordado... É o conto... É a história em quadrinhos... Enfim, é a vida sendo vivida na/pela imensidão criativa do sensível!

Não pretendemos aqui ser exaustivos nas exemplificações, até porque a vida que pulsa, o cotidiano que se instaura, a arte que se cria e as linguagens que emergem não cabem no espaço-tempo de poucas páginas deste manuscrito. Pelo contrário, nossa intenção aqui é visibilizar um pouco dessa multiplicidade, para que possamos reconhecer que os processos de ação-reflexão-ação no agir em saúde podem sim ser contagiados de afetos. E, quando conseguimos valorizá-los e operar a partir de/com/por eles, estabelecemos conexões com os sujeitos em suas inteirezas, subjetividades, espiritualidades, artisticidades, dentre outras das diversas dimensões do viver humano. Estabelecemos encontros polifônicos para a produção de sentidos.

\footnotetext{
${ }^{14}$ Linguagem cunhada e criada por Ray Lima que busca uma possibilidade de, ancorada na perspectiva da integralidade e do diálogo, construir-se uma ação social, política e pedagógica com singularidade e identidade, incorporando poesia, teatralidade, musicalidade, cenicidade, plasticidade, reflexibilidade, pedagogicidade, educabilidade. É lugar de encontro de linguagens para transler-se, transmetamoforizar-se e transnavegar em outros territórios e universos da leitura e releitura (BRASIL, 2013).
} 
Tais experiências têm trazido para o cotidiano da saúde novos sons, imagens e palavras para a produção do cuidado. Têm permitido que o contato dos profissionais de saúde com os usuários se tornem encontros de cuidado poéticos, mais humanos, demasiadamente humanos. Têm permitido que salas de espera de unidades de saúde, deixem de ser de espera, para ser de encontro criativo. Têm permitido que circulem pelas rodas de conversa não só falas racionais, mas também repentes, poemas, cirandas, passinhos - um diálogo estético em que sorrisos, abraços, lágrimas e tantas outras pulsões pulsam, com liberdade para contagiar o ambiente e ser por ele contagiado.

\section{"Muito mais importante do que chegar a uma boa solução é provocar um bom debate": questionamentos finais para que o baixar do pano daqui contagie vários outros começos daí $^{15}$}

Diante das possibilidades advindas desse exercício, que parte das nossas escrevivências coletivas, caberia aqui deixarmos algumas provocações para animar a continuidade dessa discussão sobre o lugar da arte e de suas múltiplas linguagens na EPS. Provocação-movimento que quer mobilizar a possibilidade de que cada leitor/a possa compor esse debate não só com suas ideias, pensamentos e reflexões, mas também com seus afetos, alegrias e poesias, a partir das linguagens que pedirem passagem, seja por meio de desenhos, poemas, performances, canções etc., etc., etc. e tal - permita-se, caro/a leitor/a, ser atravessado/a por elas. Convidamos, portanto, a um agir cotidiano no cuidado em saúde que, partindo da potência da arte, engendre processualidades que também se conectem pelo/com o sensível, transformando sujeitos e o mundo. Caminhos sem respostas prontas, mas sim com diversas novas perguntas:

Trabalhando em territórios onde pulsa vida, como aprender a dialogar a interagir com os corpos, os desejos e as falas e [compreender os não ditos da cultura popular?

Como traçar caminhos de luta e compromisso que se orientem por princípios [de justiça e equidade?

Como construir polifonias necessárias para o esperançar? Como incluir a [perspectiva popular?

Qual o lugar donde falamos? Quais lunetas para olhar?

Como não só elencar problemas, mas ajudar a promover reflexão?

Como tecer possibilidades pra nossa emancipação?

\footnotetext{
${ }^{15}$ Frase de Augusto Boal, fundador do Teatro do Oprimido. A segunda parte faz referência à outra provação do teatrólogo: “Arte é Política. Teatro é movimento: mostra ações humanas, atos sociais, e todas ações humanas têm sentido, meta e significado. Por que parar quando baixa o pano? Aí começa!”.
} 
Como reencantar-se, reencantar e não ficar à mercê?

Como encontrar pares para seguir, dançar, cirandar, e despertar alegres [paixões para a potencialização do ser, do existir?

Como ser sonhação?

Como criar, sorrir, cantar e incluir construindo polifonias, pra fazer pulsar [nossos afetos em expressões de alegria?

(Vera Dantas)

\section{Referências}

ALVES, I.; GONTIJO, D. T.; ALVES, H. C. Teatro do oprimido e Terapia Ocupacional: uma proposta de intervenção com jovens em situação de vulnerabilidade social. Cadernos Brasileiros de Terapia Ocupacional, São Carlos, v. 21, n. 2, p. 325-337, 2013. Doi: $10.4322 /$ cto.2013.034.

BAKHTIN, M. Estética da criação verbal. 4. ed. São Paulo: Martins Fontes, 2003.

BOAL, A. A estética do oprimido. Rio de Janeiro: Garamond, 2009.

BRASIL. Ministério da Saúde. Secretaria de Gestão Estratégica e Participativa. Comitê Nacional de Educação Popular em Saúde. Política Nacional de Educação Popular em Saúde - PNEP-SUS. Brasília: MS, 2012.

BRASIL. Ministério da Saúde. Secretaria de Gestão Estratégica e Participativa. Departamento de Apoio à Gestão Participativa. De sonhação a vida é feita, com crença e luta o ser se faz: roteiros para refletir brincando: outras razões possíveis na produção de conhecimento e saúde sob a ótica da educação popular. Brasília: MS, 2013.

COSTEIRA, A. A. de M. F.; VASCONCELOS, B. C.; NASCIMENTO, J. A. do (org.).

PalhaSUS: luta que se faz com cuidado e amorosidade. João Pessoa: Editora do CCTA, 2018.

CRUZ, N. N. Cartas para desver o conceito de resto: a cenopoesia no Hotel da Loucura. 2018. 136 f. Dissertação (Mestrado) - Programa de Pós-Graduação em Artes Cênicas, Universidade Federal do Rio Grande do Sul, Porto Alegre, 2018.

DANTAS, V. L. A. Dialogismo e arte na gestão em saúde: a perspectiva popular nas cirandas da vida em Fortaleza-CE. 2009. 323 f. Tese (Doutorado) - Programa de PósGraduação em Educação Brasileira, Universidade Federal do Ceará, Fortaleza, 2009.

FREIRE, P. Cartas a Cristina: reflexões sobre minha vida e minha práxis. São Paulo: Paz e Terra, 2015.

FREIRE, P. Pedagogia da autonomia: saberes necessários à prática educativa. 54. ed. Rio de Janeiro: Paz e Terra, 2016a.

FREIRE, P. Pedagogia do oprimido. 62. ed. Rio de Janeiro: Paz e Terra, 2016b.

LINHARES, A. M. B. O tortuoso e doce caminho da sensibilidade: um estudo sobre a arte e educação. 2. ed. Ijuí: Editora da Unijuí, 2003.

MATRACA, M. V. C.; WIMMER, G.; ARAÚJO-JORGE, T. C. Dialogia do riso: um novo conceito que introduz alegria para a promoção da saúde apoiando-se no diálogo, no riso, na 
alegria e na arte da palhaçaria. Ciência \& Saúde Coletiva, Rio de Janeiro, v. 16, n. 10, p. 4.127-4.138, 2011. Doi: 10.1590/S1413-81232011001100018.

MELO NETO, J. F. de. Extensão popular. 2. ed. João Pessoa: Editora da UFPB, 2014.

NIETZSCHE, F. Cinco prefácios para cinco livros não escritos. Tradução de P. Süssekind. São Paulo: Sette Letras, 1996.

PARO, C. A.; SILVA, N. E. K. Teatro do Oprimido e promoção da saúde: tecendo diálogos. Trabalho, Educação e Saúde, Rio de Janeiro, v. 16, n. 2, p. 471-493, 2018. Doi: 10.1590/1981-7746-sol00110.

SANTOS, E. S.; JOCA, E. C.; SOUZA, A. M. A. Teatro do Oprimido em saúde mental: participação social com arte. Interface: Comunicação, Saúde, Educação, Botucatu, v. 20, n. 58, p. 637-647, 2016. Doi: 10.1590/1807-57622015.0469.

SANTOS, M. S. Movimento Escambo: teatro e cultura popular. Contraponto, Teresina, v. 8, n. 1, p. 91-104, 2019. Disponível em:

https://revistas.ufpi.br/index.php/contraponto/article/view/9507. Acesso em: 20 maio 2020.

SILVA, P. J. P. A poética da promoção da saúde e o teatro do oprimido: percepções sobre a relevância do uso da linguagem teatral na Estratégia Saúde da Família do Complexo de Manguinhos (RJ), através da estruturação da ação-interdisciplinar teatro dentro da vida. 2008. 160 f. Dissertação (Mestrado) - Programa de Pós-Graduação em Saúde da Família, Universidade Estácio de Sá, Rio de Janeiro, 2008.

SPINOZA, B. Ética: demonstrada à maneira dos geômetras. Tradução de Joaquim de Carvalho; Joaquim Ferreira Gomes e Antônio Simões. São Paulo: Nova Cultural, 1997.

WONG-UN, J. A. De palavras-símbolo e de imagens-estrela: sobre "leveza", "incompletude" e "ser mais" no mundo pensado e imaginado da saúde coletiva. In: VASCONCELOS, E. M.; PRADO, E. V. (org.). A saúde nas palavras e nos gestos: reflexões da rede de educação popular e saúde. 2. ed. São Paulo: Hucitec, 2017. p. 240-263. 